\title{
Communication Apprehension: An Assessment of Australian and United States Data
}

\author{
B. C. Hansford and d. A. Mattie \\ University of New England. \\ Amidale, New South Nales, Australla
}

This study assessed the claims of unidimensionality for a measure of oral communication apprehension (Personal Report of Communication Apprehension). Eighteen independent samples, drawn from Australian and United States sources were used; and comparisons were made between the samples. Although similarities were found among the data sets with respect to internal consistency, frequency distributions, and item-total correlations, the claim of unidimensionality in the measure was rejected. It was also found that there were no overall differences between Australian and United States samples, no sex differences, and no age differences.

A critical and basic assumption of measurement theory is that the set of items forming a test or inventory all measure one thing in common. Besides being the basis of most mathematical measurement models, there are many reasons why unidimensionality is required if psychological sense is to be made when relating variables based on a single score from a test, when ordering persons on a specific attribute, forming groups on the basis of some variable, making observations about individual differences, or comparing total scores across populations. However, other than substantive factors can cause a test to appear nonunidimensional. For example, two persons may receive the same score on a uni-

APPLIED PSYCHOLOGICAL MEASUREMENT Vol. 6. No. 2, Spring 1982, pp. 225-233

(C) Copyright 1982 Applied Psychological Measurement Inc. 0146-6216/82/020225-09\$1.45 dimensional test, yet they may use different processing strategies to arrive at the same score, or response bias may affect their performances.

This study investigated the claim of unidimensionality made for the Personal Report of Communication Apprehension (PRCA; McCroskey, 1970), using Australian and United States samples.

\section{Communication Aprorehension}

Although a variety of instruments have been used to measure communication apprehension, the most widely reported and best documented is the PRCA-College (McCroskey, 1970). This 20-item (and, later, 25-item) inventory utilizes a Likert scaling procedure to provide a measure of the anxiety syndrome that is associated with either the real or anticipated fear of engaging in acts of communication with another person or persons. Various researchers (Garrison, Seiler, \& Boohar, 1976; McCroskey, 1970, 1978) have claimed that the PRCA is unidimensional; hence, it is meaningful to use a single score as an index of a person's communication apprehension.

In examinations of the PRCA, wo- or threefactor solutions have been reported; but because the negatively worded items load on one compo. nent and the positively worded items on the second, McCroskey's conclusion was that he did "not believe, however, that these resullts properly 
can be interpreted as an indication of multidimensionality. Rather I interpret these results ... to be indicative of two response patterns relating to item wording rather than item context" (McCroskey, 1970, p. 274). Despite these claims, McCroskey added five extra items to the original 20-item PRCA to "reduce what appeared to be a bias toward public-speaking anxiety" (Daly, 1978b, p. 205). McCroskey contended that the new items were directed toward dyadic or group communication settings, yet even with the new 25-item PRCA, "a forced twofactor solution yielded one factor composed of positively worded items and one composed of negatively worded items" (McCroskey, 1978, p. 201). McCroskey's conclusion was that the PRCA was unidimensional.

If the two factors represent such a response bias, then a one-factor solution should reflect these signs. Any further factors should be studied carefully for subgroupings of, say, public versus small group versus general reticence factors. There are various methods to check whether response bias masks latent structure, such as reversing different items, then determining whether two factors relate to the direction of the wording still appear, or making the wording ror all items go in the same direction. Moreover, maximum likelihood factor analysis hypothesizing one factor seems more appropriate for assessing dimensionality than does principal components analysis. (The latter has been used by all researchers so far.) Restricted common factor analysis can then be used to test hypotheses regarding the latent structure underlying the PRCA items (see Hattie, 1981; MCD onald, 1980; Mulaik, 1975).

As the PRCA is now being used in Australian settings, it seemed necessary to reassess the properties of the instrument in a different cultural setting and to compare the findings with those reported in United States studies. Or particular interest was the distributions of scores, the reliability, the difference in means between United States and Australian samples, and the factorial structure.

\section{Method}

This study utilized both the 20- and 25-item versions of PRCA-College, and in both versions a five-point response scale is used, ranging from a possible choice of "strongly agree" to "strongly disagree" (see "Table 6 for items). As 13 samples $(N=1,784)$ were used in the study, it was possible to test many hypotheses, cross-validate results, and thus enhance generalizability. Samples 1 to 12 were collected in Australia over a period of 6 months, and the 13 th sample was based on data made available by McCroskey (see Table 1). The 20-item PRCA-College was administered to Samples 1 to 5. These five samples consisted, respectively, of 12 th year students, telephone counselors at the start of a training course, university students, adult males, and adult females. Samples 6 and 7 were also administered the 20-item PRCA, but some items were changed from positively to negatively directed (see Results section). These two samples used part-time university students drawn from a broad age range and representing a variety of backgrounds. Samples 8 to 12 were administered the 25-item PRCA. Sample 8 were the telephone counselors at the completion of their training course. Samples 9 to 12 were 12 th year students, with Samples 9 and 10 being administered a version of the PRCA with all the items worded in the same direction (see Results section). Details regarding the sample provided by McCroskey (Sample 13) are currently unknown; but on the basis of other tests administered to the group, it would seem that they were probably college or university students.

Table 1 presents the summary statistics for each sample. It should be noted that ive additional samples of United States data were extracted from the literature. Two samples were obtained from the Beatty, Behrke, and McCallum (1978) study; two from the Daly (1978b) study; and one from the McCroskey (1970) study. Information regarding these samples is not reported in Table 1, but these data are included at various stages of the analysis. 
Table 1

Characteristics of Samples 1 to 13 and Sumary Statistics

\begin{tabular}{|c|c|c|c|c|c|c|c|c|c|c|c|c|c|}
\hline \multirow[b]{2}{*}{ Sample } & \multirow[b]{2}{*}{ Characteristic } & \multirow[b]{2}{*}{$\mathrm{N}$} & \multirow[b]{2}{*}{ Mean } & \multirow[b]{2}{*}{ SD } & \multirow[b]{2}{*}{ Median } & \multirow{2}{*}{$\begin{array}{l}\text { Skew- } \\
\text { ness }\end{array}$} & \multirow{2}{*}{$\begin{array}{l}\text { Kur- } \\
\text { tosis }\end{array}$} & \multicolumn{2}{|c|}{ Range } & \multicolumn{3}{|c|}{ Item Iotal $\mathrm{r}$} & \multirow{2}{*}{$\begin{array}{l}\mathrm{KR} \\
20\end{array}$} \\
\hline & & & & & & & & MIn & $\operatorname{Max}$ & Low & High & Mean & \\
\hline 1 & Year 12 & 294 & 58.08 & 11.56 & 58 & .03 & .08 & 25 & 91 & .40 & .64 & .53 & .86 \\
\hline 2 & Adults, Males & 106 & 58.19 & 14.09 & 56 & .34 & -.67 & 29 & 89 & .43 & .75 & .62 & .91 \\
\hline 3 & Adults, Female & 154 & 62.53 & 15.39 & 63 & -.30 & -.08 & 24 & 98 & .45 & .77 & .65 & .92 \\
\hline 4 & Telephone Counselors & 76 & 58.82 & 13.96 & 60 & -.01 & -.55 & 30 & 86 & .39 & .82 & .64 & .92 \\
\hline 5 & University & 49 & 60.31 & 12.23 & 59 & .31 & -.50 & 38 & 90 & .27 & .75 & .59 & .90 \\
\hline 6 & University Males & 43 & 58.00 & 10.18 & 59 & -.12 & .12 & 29 & 75 & .25 & .72 & .51 & .84 \\
\hline 7 & University Females & 42 & 58.02 & 14. & 57 & .07 & -.80 & 29 & 82 & .18 & .84 & .61 & .90 \\
\hline 8 & Telephone Counselors & 32 & 72.93 & 14.63 & 72 & .12 & -.09 & 42 & 103 & .38 & .75 & .60 & .92 \\
\hline 9 & Year 12 Males & 52 & 67.79 & 11.70 & 65 & .24 & -.53 & 46 & 95 & .14 & .67 & .46 & .83 \\
\hline 10 & Year 12 Females & 81 & 69.23 & 13.42 & 68 & -.36 & -.35 & 35 & 95 & .23 & .72 & .52 & .89 \\
\hline 11 & Year 12 Males & 48 & 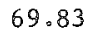 & 4.59 & 69 & .19 & .18 & 58 & 81 & .21 & .70 & .48 & .85 \\
\hline 12 & Year 12 Females & 69 & 69.71 & 5.04 & 69 & -.07 & -.16 & 58 & 82 & .15 & .81 & .59 & .91 \\
\hline 13 & McCroskey (College) & 738 & 14.02 & tots & $* \%$ & Whe & \% & 31 & 114 & 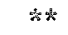 & 类宔 & $* \%$ & *\% \\
\hline Total, & Samples 1 to 7 & 764 & 59.20 & 12.65 & 59 & .09 & .07 & 24 & 98 & .32 & .77 & .60 & .90 \\
\hline Total, & Samples 8 to 12 & 282 & 69.60 & 9.69 & 68 & .03 & -.10 & 42 & 103 & .34 & .66 & .58 & .88 \\
\hline
\end{tabular}

*Mean correlation based on $\underline{r}$ to $\underline{z}$ transformations.

**Not available.

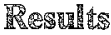

\section{Propertiles of PRAR-Comllege}

As can be observed in Table 1 , there was a range in the estimated reliability values (KuderRichardson 20) from .83 (lower bound) for Sample 9 to .93 (upper bound) for Samples 4 and 8. Studies reported in the United States (Daly, 1978a, 1978b; Garrison et al., 1976; McCroskey, 1970) also indicated that high estimated reliability values $(.92$ to .94$)$ have been obtained.

The average corrected item-total correlations are reported in Table 1 and these were significantly different from zero $(\alpha=0.001)$ for all samples, hence confirming MoCroskey's (1970) original contention that only significantly contributing items were retained in the final version of the PRCA.

In the case of the 25-item PRCA, it can be observed (Table 1) that scores ranged from 46 to 103 as compared with the hypothetical range of 25 to 125 . The 20-item PRCA has a hypothetical range of 20 to 100 , and the scores from the Australian samples ranged from 24 to 98 . No skewness indices were significantly different from zero; and in all samples, the median differed from the mean by no more than three score units. The near normality of score distribution is similar to the evidence reported by McCroskey (1970, 1978) and Moore (1972).

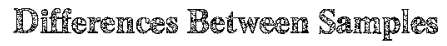

Three analyses of variance were calculated to ascertain whether differences existed between the means of the samples. First, Samples 1 to 7 were used to check on differences between the means of the 20-item instrument; second, Samples 8 to 13 related to differences on the 25 item instrument and between the Australian and United States samples; and third, the means of the 20 -item instrument were prorated to a mean for 25 items, and all 13 samples plus the five extra United States literature samples were compared.

There were significant differences between means of Samples 1 to 7 for the 20 -item PRCA $(F[6,757]=2.51, p=.02)$; but Scheffé contrasts between each pair of sample means did not reveal any pattern, nor were there differences between the male and female means. The maxi- 
mum difference between the means was 4.53 , which was approximatelly one-third of a standard deviation-a negligible difference.

An analysis of variance between the six samples completing the 25-item PRCA revealed significant differences $(F[5,1014]$ $=2.36, p=.04)$. Again, Scheffé contrasts revealed no differences between pairs of means, and the overall mean for the male samples did not differ from the female samples. The maximum difference between the means was 5.14, which is approximately one-half a standard deviation.

The analysis of variance of the 13 samples plus the additional United States literature $(N=4,542)$ revealed differences between the means $(F[17,4524]=7.66, p<.001)$. Scheffé contrasts between various pairs of means indicated there were no differences between the Australian and United States samples means, the male and female means, the adult and university student means, and the college and university student means.

Based on the results of these analysis of variance, it was concluded that with respect to PRCA-College responses there were no differences between the Australian and United States samples, no sex differences, and no age differences.

\section{Factor Structure of PRCA-College}

The objective was to explore the underlying latent structure of the PRCA. In particular, the intention was to assess whether the PRCA is unidimensional. Unrestricted common factor analysis was used in the initial data analysis; this was followed by application of restricted common factor analysis, the results from which were crossvalidated.

The first step related to assessing the number of factors underlying the data. Table 2 presents the $\chi^{2}$ statistic, associated degrees of freedom, and for ease of reference the $\chi^{2}$ is transformed into a $z$ score $(a=.01 \equiv z=2.58)$ for the first five samples, i.e., for the 20-item PRCA (using COFA; McDonald, 1974). Clearly, in terms of goodness of fit, at least four factors were necessary. The average congruence coefficient of the four factors over the first five samples $(.98, .92$, .88 , and .55) indicated that whatever the factors represented was replicated across the five samples, at least for the first three factors.

For the one-factor solution all the signs were reproduced as expected, yet there were large and patterned residuals. The two-factor solution appeared to relate to item direction; but it was noted that nearly all the positively worded items related to speaking in front of large groups and

Table 2

$x^{2}$, Degrees of Freedom (df), and $z$ Statistics for Testing the Hypothesis That There Are $k$ Factors, Where $k=1$ to 5 , for the 20-Item PRCA, for Samples 1 to 5

\begin{tabular}{|c|c|c|c|c|c|c|c|c|c|c|}
\hline \multirow[b]{3}{*}{ Sample } & \multicolumn{10}{|c|}{ Number of Factors } \\
\hline & $\left(\mathrm{df}^{1}=\right.$ & 170) & $\left(\mathrm{df}^{2}=\right.$ & 151) & $\left(d f^{3}=\right.$ & 133) & $(d f$ & $\begin{array}{l}4 \\
=116)\end{array}$ & $\left(d^{5}=\right.$ & 100) \\
\hline & $x^{2}$ & $\underline{z}$ & $x^{2}$ & $\underline{z}$ & $x^{2}$ & $\underline{z}$ & $x^{2}$ & $\underline{z}$ & $x^{2}$ & $\underline{z}$ \\
\hline 1 & 424.77 & 9.91 & 285.74 & 6.21 & 217.54 & 4.40 & 154.9 & 52.36 & 116.99 & 1.99 \\
\hline 2 & 353.34 & 7.68 & 273.52 & 5.75 & 208.86 & 4.01 & 165.0 & 152.98 & 132.66 & 2.14 \\
\hline 3 & 453.66 & 10.74 & 287.98 & 6.30 & 198.88 & 3.55 & 148. & 61.86 & 116.62 & 1.16 \\
\hline 4 & 286.55 & 5.29 & 221.52 & 3.59 & 175.49 & 2.41 & 144.2 & 51.77 & 110.68 & .78 \\
\hline 5 & 296.60 & 5.67 & 221.86 & 3.61 & 174.98 & 2.38 & 131.9 & 61.05 & 111.44 & .83 \\
\hline
\end{tabular}


negatively worded items related to speaking before small groups or to general nervousness.

In the three-factor solution, there appeared to be a communication apprehension in large group factor, a nervous and tense factor, and an anticipation to communicate factor. The first and third factors both related to large groups, yet Factor 1 refers primarily to apprehension while speaking and Factor 3 refers to anticipated apprehension of speaking (e.g., "My thoughts become confused and jumbled when I speak before an audience" versus "I look forward to an opportunity to speak in public').

When the four-factor solution was considered, the previous three factors were evident, but the fourth factor was difficult to interpret. It should be noted that the congruence coefficient was also very low.

As some doubt existed concerning the meaning of the two-factor solution, it was decided to discriminate between the two major conjectures: (1) that one factor represented the positively worded items and the other factor represented the negatively worded factors or (2) that one factor represented communication apprehension relating to large groups and the other factor represented communication relating to small groups or general nervousness.

McDonald and Leong's (1976) analysis of covariance structures methods were used to test these two hypotheses. For the first hypothesis, all the positively worded items on the first factor were free to be estimated and the negatively worded items were constrained to zero, and vice versa on the second factor. For the second hypothesis, the first and third factor from the three-factor unrestricted solution were constrained to load on the first factor, the second factor from the unrestricted solution loaded on the second factor, and Item 8 was free to be estimated on both factors. The $\chi^{2}$, degrees of freedom, and $z$ statistics are presented in Table 3. $\left(\Delta \chi^{2}\right.$ is a measure of whether the two models are significantly different; $\Delta \chi^{2}=\chi^{2} 1-\chi^{2} 2$ with $\Delta d f=d f_{1}-d f_{2}$.) It should be noted that although there were two factors relating to the first hypothesis and three relating to the second hypothesis, the difference in the degrees of freedom incorporated this difference. Further, as only one sample was used, the probabilities of the $\chi^{2}$ are only approximate.

Although the hypothesized pattern matrices were different, convincing evidence did not exist as to which of the competing hypothesis was to be preferred.

The problem may be that the two hypothesized pattern matrices were not different enough, so various item directions were changed in order to maximize the different hypothesized patterns and these items were administered to

\begin{tabular}{|c|c|c|c|c|c|c|}
\hline \multirow[b]{2}{*}{ Sample } & \multicolumn{2}{|c|}{$\begin{array}{l}\text { Positive Versus } \\
\text { Negative Wording } \\
\qquad(\mathrm{df}=119)\end{array}$} & \multicolumn{2}{|c|}{$\begin{array}{l}\text { Large Versus } \\
\text { Sma11 Group } \\
(\mathrm{df}=168) \\
\end{array}$} & \multirow[b]{2}{*}{$\Delta x^{2}$} & \multirow[b]{2}{*}{$\underline{z}$} \\
\hline & $x^{2}$ & $\underline{z}$ & $x^{2}$ & $\underline{z}$ & & \\
\hline 1 & 335.47 & 7.54 & 394.99 & 9.80 & -59.52 & 9.91 \\
\hline 2 & 335.13 & 7.53 & 326.78 & 7.26 & 8.35 & 3.09 \\
\hline 3 & 348.02 & 8.03 & 433.94 & 11.16 & 85.92 & 12.11 \\
\hline 4 & 271.66 & 4.95 & 261.46 & 4.56 & 10.20 & 3.52 \\
\hline 5 & 342.65 & 7.82 & 279.39 & $5 \cdot 34$ & 63.26 & 10.24 \\
\hline
\end{tabular}

Downloaded from the Digital Conservancy at the University of Minnesota, http://purl.umn.edu/93227. May be reproduced with no cost by students and faculty for academic use. Non-academic reproduction requires payment of royalties through the Copyright Clearance Center, http://www.copyright.com/ 
Samples 6 and 7. The resultant $\Delta x^{2}$ were 1.25 and -4.89 for Samples 6 and 7 , respectively. Although there was no clear evidence as to which pattern should be preferred, it was established that the large versus small group hypothesis is tenable as an alternative to the item-wording hypothesis. Further, it was clear that changing the direction of wording on various items could improve the fit.

In an attempt to overcome an apparent public-speaking bias in the PRCA, McCroskey added five items to the scale. This raised the question as to whether these extra items clarified the latent structure. To assess the number of factors, exploratory maximum likelihood factor analysis were run on Samples 9 to 13 (Table 4). Given the small sample size of 32 , the telephone counselors were excluded from this exploratory analysis. An examination of the data in Table 4 suggests that the two- or three-factor solution was minimal.

Given the previous hypothesis and that $\mathrm{Mc}$ Croskey added four items relating to communiation in groups and an item dealing with com- munication reticence, the following hypotheses were tested using confirmatory factor analysis:

Hypothesis 1: That Factor 1 related to the negativelly worded items, and Factor 2 related to the positively worded items:

Hypothesis 2: That Factor 1 related to communication apprehension in large groups, Factor 2 related to communication apprehension in small or unstructured groups, and Factor 3 related to general reticence to communicate or self-consciousness when communicating. (In both hypotheses the factors were allowed to correlate.)

Samples 8, 9, 10, and 13 were administered the 25 items; the goodness-of-fit statistics are presented in Table 5. Samples 11 and 12 were administered the 25 items with all the items keyed in the same direction, and the goodness-of-fit statistics are also presented in Table 5.

For all six samples, Hypothesis 2 had a significantly better fit than Hypothesis 1 . Hence, it was

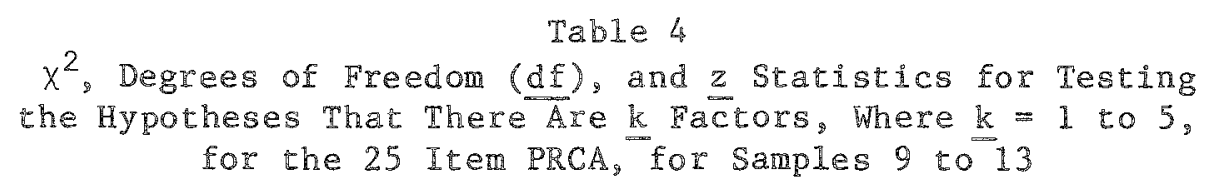

\begin{tabular}{|c|c|c|c|c|c|c|c|c|c|c|}
\hline \multirow[b]{4}{*}{ Sample } & \multicolumn{10}{|c|}{ Number of Factors } \\
\hline & \multirow{2}{*}{\multicolumn{2}{|c|}{$(d f=275)$}} & \multirow{2}{*}{\multicolumn{2}{|c|}{$\begin{array}{c}2 \\
(d f=251)\end{array}$}} & \multirow{2}{*}{\multicolumn{2}{|c|}{$(\mathrm{df}=228)$}} & \multicolumn{2}{|c|}{4} & \multirow{2}{*}{\multicolumn{2}{|c|}{$\begin{array}{c}5 \\
(d f=185)\end{array}$}} \\
\hline & & & & & & & $(d f=$ & $206)$ & & \\
\hline & $x^{2}$ & $\underline{z}$ & $x^{2}$ & $z$ & $x^{2}$ & $\underline{z}$ & $x^{2}$ & $\underline{z}$ & $x^{2}$ & 2 \\
\hline 9 & 375.55 & 3.88 & 318.43 & 2.80 & 276.00 & 2.14 & 233.30 & 1.32 & 211.55 & 1.35 \\
\hline 10 & 521.50 & 8.39 & 396.20 & 5.55 & 333.34 & 4.35 & 289.03 & 3.67 & 246.94 & 2.95 \\
\hline 11 & 358.43 & 3.28 & 279.21 & 1.24 & 245.90 & .85 & 211.59 & .31 & 184.92 & .03 \\
\hline 12 & 446.78 & 6.21 & 326.15 & 3.10 & 282.15 & 2.39 & 240.16 & 1.61 & 201.14 & .85 \\
\hline 13 & 1330.76 & 24.35 & 783.55 & 15.54 & 509.36 & 9.87 & 393.77 & 7.37 & 307.75 & 5.37 \\
\hline
\end{tabular}


Table 5

$x^{2}$, Degrees of Freedom ( $\left.\mathrm{df}\right)$, and $z$ Statistics Relating
to the Two Hypotheses and the bifference Between the
$x^{2}$ Values ( $\Delta x^{2}$ with 9 df), for Samples 8 to 13

\begin{tabular}{|c|c|c|c|c|c|c|}
\hline \multirow[b]{2}{*}{ Sample } & \multicolumn{2}{|c|}{$\begin{array}{c}\text { Hypothesis } 1 \\
(\mathrm{df}=274)\end{array}$} & \multicolumn{2}{|c|}{$\begin{array}{l}\text { Hypothesis } 2 \\
(\mathrm{df}=165)\end{array}$} & \multirow[b]{2}{*}{$\Delta x^{2}$} & \multirow[b]{2}{*}{$\underline{z}$} \\
\hline & $x^{2}$ & $\underline{z}$ & $x^{2}$ & $\underline{z}$ & & \\
\hline 8 & 479.62 & 7.58 & 393.30 & 5.05 & 86.32 & .99 \\
\hline 9 & 378.26 & 4.12 & 356.92 & 3.72 & 21.34 & .99 \\
\hline 10 & 522.77 & 8.95 & 420.64 & 6.00 & 102.13 & .99 \\
\hline 11 & 365.96 & 3.67 & 327.02 & 2.57 & 38.94 & .99 \\
\hline 12 & 453.08 & 6.71 & 363.79 & 3.97 & 89.29 & .99 \\
\hline 13 & 1226.64 & 26.14 & 862.09 & 18.52 & 364.55 & .99 \\
\hline
\end{tabular}

concluded that in lieu of a better hypothesis, the underlying structure of the PRCA includes factors relating to communication apprehension in large groups, communication apprehension in small or unstructured groups, and a general reticence to communicate or self-consciousness when communicating.

The average factor loadings and uniquenesses are reported in Table 6. All signs were in the expected direction, the average off-diagonal residual was .087 , and the average diagonal residual was .004 . There was a high correlation between Factors 1 and 3, yet when the correlations between all factors were constrained to zero, there was still a better fit for the three orthogonal factors compared to Hypothesis 1 . The average congruence coefficients between the factors across the six samples were all high on the diagonals (average.76) and extremely low on the off-diagonals (average.002).

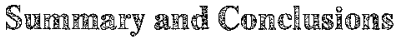

Data from both the 20- and 25-item PRCA were collected from a variety of samples in dif- ferent situations. Im summary, it can be concluded that the item-total correlations were high, there was an approximate normal distribution of test scores, there were no differences in means between Australian samples nor between Australian and United States samples, there were no sex differences, the PRCA is mot unidimensional, and there are three factors underlying the PRCA in both the Australian and United States Samples. The three ractors related to communication apprehension in small groups, communication apprehension in large groups, and a general reticence to communicate. The previous conjecture by McCroskey and others that there was a unidimensional structure only compounded by the positive and negative wording of the items was not supported. Because of the varied samples, these conclusions can be generalized to a broad domain of people and conditions. Both cross-validation and double cross-validation (Mosteller \& Tukey, 1977) were employed, and sample sizes were large enough to ensure that the statistics used were sufficiently powerful. 
Table 6

Average Factor Loadings and Uniquenesses Across the Six Samples for Hypothesis 2

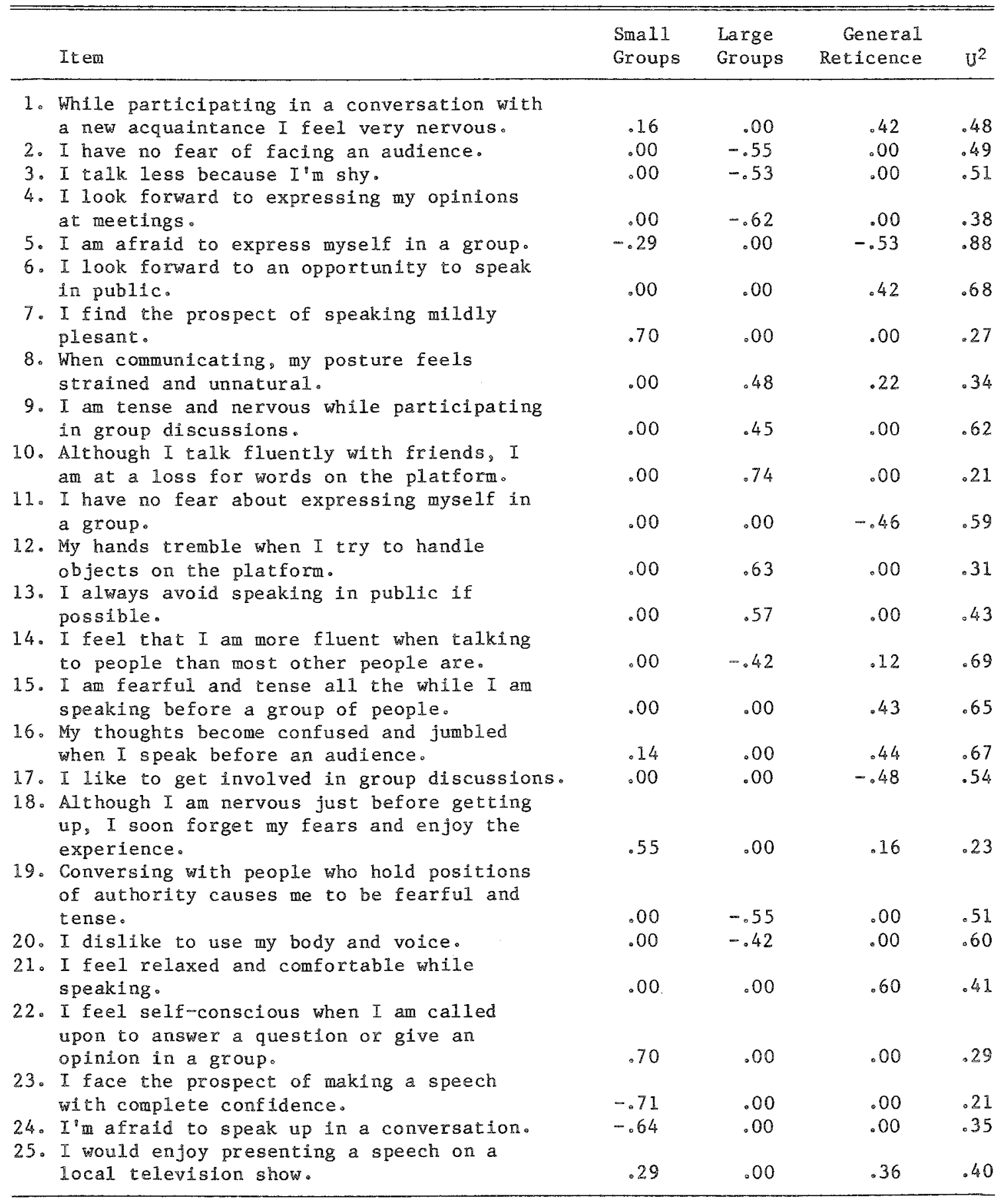

Downloaded from the Digital Conservancy at the University of Minnesota, http://purl.umn.edu/93227. May be reproduced with no cost by students and faculty for academic use. Non-academic reproduction requires payment of royalties through the Copyright Clearance Center, http://www.copyright.com/ 


\section{References}

Beatty, M. J., Behnke, R. R., \& MeCallum, K. Situational determinants of communication apprehension. Communication Monographs, 1978, 45, 187-191.

Daly, J. A. Communication apprehension and behavior: Applying a multiple act criteria. Human Communication Research, 1978, 4, 208-216. (a)

Daly, J. A. The assessment of social-communicative anxiety via self-reports: A comparison of measures. Communication Monographs, 1978, 45, 204-218. (b)

Garrison, J. P., Seiler, W. J., \& Boohar, R. K. The effects of talking apprehension on student academic achievement. Three empirical investigations in communication-restricted and traditional laboratory classes in life sciences. Communication Yearbook, 1976, 1, 513-524.

Hattie, J. A. A four stage factor analytic approach to studying behavioral domains. Applied Psychological Measurement, 1981, 5, 77-88.

McCroskey, J. C. Measures of communication-bound anxiety. Speech Monographs, 1970, 37, 269-277.

McCroskey, J. C. Validity of the PRCA as an index of oral communication apprehension. Communication Monographs, 1978, 45, 192-203.

McDonald, R.P. A common factor analysis program. Toronto: OISE, 1974.
McDonald, R. P., \& Leong, K. S. COSA: An analysis of covariance structures program. Toronto: OISE, 1976.

McDonald, R. P. A simple comprehensive model for the analysis of covariance structures: Some remarks on applications. British Journal of Mathematical \& Statistical Psychology. 1980, 33, 161-183.

Moore, $\mathbb{D}$. $\mathbb{L}$. The effects of systematic desensitization of communication apprehension in an aged population. Unpublished master's thesis, Illinois State University, 1972.

Mosteller, F., \& Tukey, J. W. Data analysis and regression: A second course in statistics. Reading MA: Addison-Wesley, 1977.

Mulaik, S. A. Confirmatory factor analysis. In $\mathrm{H}$. Walberg \& D. Amick (Eds.), Introductory multivariate analysis. San Francisco: McCutchan, 1975.

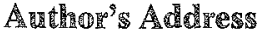

Send requests for reprints or further information to B. C. Hansford, Centre for Behavioural Studies in Education, University of New England, Armidale 2351, New South Wales, Australia. 